Rabaska

Revue d'ethnologie de l'Amérique française

GuAy, LORRAINE. Le Québec des îles. Québec, Les Presses de l'Université Laval, "Les régions du Québec », 2011, 192 p. ISBN : 978-2-7637-9230-9

\title{
Georges Larouche
}

Volume 10, 2012

URI : https://id.erudit.org/iderudit/1013566ar

DOI : https://doi.org/10.7202/1013566ar

Aller au sommaire du numéro

Éditeur(s)

Société québécoise d'ethnologie

ISSN

1703-7433 (imprimé)

1916-7350 (numérique)

Découvrir la revue

Citer ce compte rendu

Larouche, G. (2012). Compte rendu de [GUAY, LoRRAINE. Le Québec des îles. Québec, Les Presses de l’Université Laval, « Les régions du Québec », 2011,

192 p. ISBN : 978-2-7637-9230-9]. Rabaska, 10, 258-259.

https://doi.org/10.7202/1013566ar d'utilisation que vous pouvez consulter en ligne.

https://apropos.erudit.org/fr/usagers/politique-dutilisation/ 
renseigne sur la richesse de l'imaginaire des Écossais de la Nouvelle-Écosse aux siècles derniers. Cependant, on peut lui reprocher quelques lacunes. En plus d'énumérer de nombreux thèmes légendaires, l'auteur aurait pu au moins développer une conclusion en analysant même brièvement ses découvertes. Aussi, comme le fait remarquer Ian Brodie, Fraser se montre inconstante dans l'usage de ses sources, les citations étant réduites au minimum et souvent incomplètes. Heureusement, Brodie a tenté de les rétablir en donnant des références plus complètes. Il avoue cependant qu'il s'est quelquefois basé sur des suppositions éclairées (p. xx). En outre, l'auteur a souvent omis le nom de plusieurs informateurs pour garder l'anonymat; et lorsque le nom est donné, le lecteur ne connaîtra ni son âge, ni son lieu d'origine, ni la date de la cueillette du récit, toutes des informations que le spécialiste aurait jugées essentielles. En dépit de ses lacunes, la nouvelle édition de ce recueil permet de faire connaître l'auteur, Mary Fraser, une religieuse qui a joué un rôle important dans la cueillette de matériel folklorique en Nouvelle-Écosse, et de l'ajouter à la liste des femmes collectrices au Canada.

Carmen d'Entremont

Université Sainte-Anne

Guay, Lorraine. Le Québec des îles. Québec, Les Presses de l'Université Laval, «Les régions du Québec », 2011, 192 p. ISBN : 978-2-7637-9230-9.

Ce petit livre est un ouvrage de vulgarisation dépouillé de l'érudition qui caractérise le précédent ouvrage du même auteur publié en 2003, dans le cadre du chantier des histoires régionales du Québec, intitulé À la découverte des îles du Saint-Laurent. De Cataracoui à Anticosti (Éditions du Septentrion, 2003, 400 p.). Ce titre aurait pu être appliqué au présent ouvrage de vulgarisation, vu que le sujet ne concerne pas autre chose que le Saint-Laurent et ses îles. Le Québec des îles surprend, au premier abord, mais peut se justifier par le fait que le dernier chapitre intitulé « Les habitants du Saint-Laurent » est le plus long des cinq qui composent le livre.

On y trouvera une foule de renseignements sur les îles continentales et maritimes ( $\mathrm{D}$ 'îles en archipels »), leurs définitions (« Des terres en mouvance »), les aspects mythiques et tragiques des îles ("Rêves et cauchemars »), les guerres et le commerce (« Des postes stratégiques ») et, pour finir, « Les habitants du Saint-Laurent $»$ où l'on trouvera quelques paragraphes relatifs à l'ethnographie. L'auteur s'appuie sur une bibliographie diversifiée et termine l'ouvrage par une énumération de repères chronologiques fort appréciés dans les livres d'histoire. Sauf l'emploi fautif du verbe essaimer, utilisé transitivement (p. 131), sans doute à cause d'une lacune dans la transcription du texte, et l'absence de la préposition par devant celui du bois (p. 122), le texte 
semble impeccable.

La faiblesse du livre réside dans sa présentation matérielle. Les caractères trop petits de la carte du fleuve nécessitent pratiquement l'emploi d'une loupe et la plupart des quatre-vingt-huit photos laissent à désirer, de par leur teinte bleutée ou grisâtre. Sans doute pour atténuer le caractère aride du sujet, la maquettiste a introduit, à intervalles réguliers, des pages bleutées et des rectangles bleu foncé sous les photos. Dans l'ensemble, ce livre très instructif peut être utilisé comme un vade-mecum pratique des îles du Saint-Laurent.

Georges Larouche

Beauport, Québec

Lemasson, Jean-Pierre. L'Incroyable Odyssée de la tourtière. Montréal, Amérik Media, 2011, 166 p. ISBN 978-2-923543-18-5.

Quelle est donc la véritable identité de ce plat dont Jacques Rousseau disait qu'on était passé, au Québec, « du contenant au contenu » ? S'agit-il de la tourtière du Lac-Saint-Jean, aussi appelée cipaille, cipâte ou six-pâtes, ou de la tourtière de porc que d'aucuns nomment «pâté à la viande »?

Jean-Pierre Lemasson, professeur à l'UQÀM et responsable du Certificat en gestion et pratiques socioculturelles de la gastronomie, s'est penché sur la question. Après nous avoir fait découvrir « l'incroyable odyssée » de ce plat qui « se perd dans la nuit des temps », il apporte une réponse qui a le grand mérite d'être explicite, bien que sa position soit beaucoup plus nuancée dans un article paru précédemment sur le Web (« Tourtière du Lac-Saint-Jean », Encyclopédie du patrimoine culturel de l'Amérique française, 2007). Faut-il voir dans le livre publié en 2011 le résultat d'une réflexion plus poussée que dans l'article de 2007 ?

La méthode est rigoureuse. Elle repose sur la consultation d'ouvrages d'historiens chevronnés et sur des sources documentaires difficilement contestables : les livres de cuisine. L'auteur nous convie à un voyage dans le temps. L'ouvrage n'a peut-être que 166 pages, mais il couvre 6000 ans d'histoire et il ne faut pas croire qu'il soit superficiel pour autant. N'oublions pas que le sujet est pointu. Lemasson fait remonter son origine en Mésopotamie, environ 1700 ans av. J.-C. Aucun autre plat, affirme-t-il, « ne peut prétendre avoir été au commencement de notre civilisation ».

Le livre se divise en six chapitres complétés par des recettes de tourtes et de tourtières (en annexe). Tout au long de cette plongée dans le passé, l'auteur décrit l'évolution de la tourte à travers les siècles en suivant un fil conducteur qui nous ramène toujours à son archétype, c'est-à-dire un plat composé de trois éléments essentiels : une abaisse, un appareil et une seconde abaisse 